\title{
Dos Museus dos Descobrimentos às Exposições do Império: o Corpo Colonial em Portugal
}

\author{
Mariana Selister Gomes' (iD 0000-0001-6837-9158
}

'Universidade Federal de Santa Maria, Santa Maria, RS, Brasil.97105-900-dcs@ufsm.br

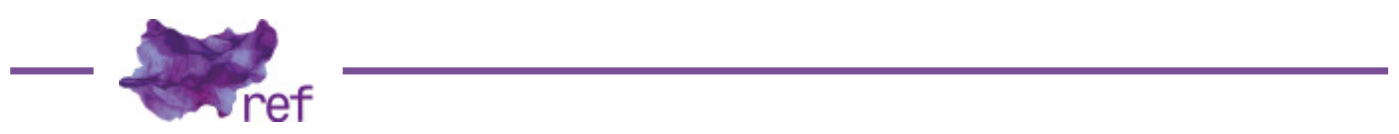

Resumo: O artigo se insere nos debates sobre a memória do colonialismo português, analisando-a a partir da Interseccionalidade entre Gênero, Raça e Sexualidade. São investigadas as narrativas em torno do Corpo Colonial dos Museus dos Descobrimentos Portugueses, a fim de perceber em que (des)(re)constroem discursos das Exposições do Império Português. A metodologia segue uma inspiração na analítica foucaultiana dos discursos: a arque-genealogia. Como técnicas de pesquisa, são utilizadas: observação direta e entrevistas, no caso dos Museus; e a análise documental histórica em fontes secundárias, no caso das Exposições. As conclusões apontam que há uma tentativa de deslocamento discursivo por parte dos Museus, os quais buscam dissociar Descobrimentos e Colonização. No entanto, há elementos discursivos que se repetem, como a nudez e o exotismo, reconstruindo a Colonialidade dos Corpos de origem não europeia.

Palavras-chave: corpo colonial; museus; Portugal; discursos

From the Museums of the Discoveries to the Exhibitions of the Empire: The Colonial Body in Portugal

Abstract: This paper is inserted in the current debates on the memory of Portuguese colonialism. This memory is analyze it from the Intersectionality between Gender, Race and Sexuality. The focus is on the narratives around the Colonial Body present in the Portuguese Discoveries Museums and the Exhibitions of the Portuguese Empire. The methodology follows an inspiration in the Michel Foucault analysis of the discourses. As research techniques, it is used: direct observation and interviews, in the case of Museums; and, the historical documentary analysis in secondary sources, in the case of Exhibitions. The conclusions point out that there is an attempt of discursive displacement on the part of the Museums, which seek to dissociate Discoveries and Colonization. However, there are also many repeating discursive elements, such as nudity and exoticism, rebuilding the Coloniality of Bodies of non-European origin.

Keywords: Colonial Body; Museums; Portugal; Discourses.

\section{Introdução}

O tema da memória do colonialismo português tem recebido atenção da grande mídia (André BARATA, 2018; Bruna BORELLI, 2018; Isabel SALEMA, 2018). Críticas empreendidas por acadêmicos como Cláudia CASTELO (1998) e Miguel Vale de ALMEIDA (2000), e pela ONU (Jamil CHADE, 2012), de que Portugal exalta o passado colonial de forma acrítica, estão ganhando repercussão. Neste cenário, emergem disputas sobre museus e memoriais.

Esse entendimento de que os museus são espaços de disputas simbólicas não é recente. No início do século XX, as Sufragistas, militantes que buscavam o direito ao voto na Inglaterra, invadiram Museus britânicos para danificar obras e denunciar a forma inferiorizada que retratavam as mulheres (Beatriz MONTESANTI, 2015). Naquela que ficou conhecida como a Primeira Onda do Movimento Feminista, os museus já foram entendidos como importantes espaços de embate social. Cabe lembrar a obra de Lynda NEAD (1992), a qual demonstra como a nudez feminina é marcante 
na história da arte ocidental, sendo objeto de disputa de significados, mecanismo de controle dos corpos das mulheres e ferramenta de libertação do feminismo.

Contemporaneamente ao Movimento Sufragista, realizou-se em Portugal, em 1934, uma Exposição para exaltar o Império Português, que ainda ocupava territórios africanos e asiáticos. Foram levados, das colônias para a metrópole, diversos produtos e espécies. Entre estes, estavam mulheres. Nuas. Expostas. Objetificadas. Fato semelhante ocorreu no Império Britânico, como no caso de Saartjie Baartman, a Vênus Hotentote (Anne McCLINTOCK, 2010), mulher sul-africana que foi exposta em zoológicos e circos na Europa, no século XIX. Estes casos podem ser compreendidos a partir do conceito de corpo colonial.

O corpo colonial é um corpo construído como disponível (Maria LUGONES, 2008; Alejandro OTO, 2006). O corpo da mulher foi historicamente construído como disponível ao homem, o que ainda se traduz em diferentes formas de violência (Beatriz SANTOS, 2017). O corpo dos africanos e indígenas escravizados também fora construído como disponível aos colonizadores brancos, o que sustentou uma série de atrocidades ao longo dos séculos, inclusive a nível subjetivo (Frantz FANON, 1983). Nesta intersecção, o corpo da mulher colonizada, negra e indígena fora aquele mais vitimado, construído como corpo colonial disponível. Ressalta-se que este olhar colonial sobre o corpo das mulheres é reproduzido em diferentes discursos atualmente e influencia a experiência de mulheres de ex-colônias que migram para as ex-metrópoles, como demonstram Mariana GOMES; Beatriz PADILLA; Gleiciane FERNANDES, 2017; Carmen GREGÓRIO-GIL, 2009. Compreendendo-se que discursos são práticas que correspondem a uma ordem de saber-poder e a exercícios do poder, que implicam uma correlação desigual de forças (Michel FOUCAULT, 2004; 2008). Entende-se que a construção discursiva do corpo colonial é uma forma de violência contra as mulheres. Uma violência simbólica (Pierre BOURDIEU, 2006). Uma violência enquanto ordem discursiva hegemônica (FOUCAULT, 2008) que inferioriza as mulheres. Uma violência enquanto construção histórica e normativa de gênero (Joan SCOTT, 1986). Neste sentido, justifica-se a importância de refletir sobre a (re)(des)construção de discursos coloniais em museus atuais, em diálogo com construções históricas, como é feito neste artigo.

A partir de discussões teóricas e de pesquisas empíricas, busca-se realizar, neste artigo, uma arque-genealogia do corpo colonial, através da análise de narrativas expográficas. Parte-se da análise de Museus dos Descobrimentos Portugueses, ${ }^{1}$ localizados em Belmonte e no Porto, com o objetivo de perceber quais os discursos emergem em suas exposições e quais suas conexões com as narrativas das Exposições do Império Português, buscando refletir, de forma não linear, sobre as (re)(des)construções do corpo colonial.

A metodologia empregada foi a Análise de Discurso de inspiração foucaultiana ou a Arque-genealogia. Em síntese, é possível afirmar que Arqueologia do Saber (FOUCAULT, 2004) e a Genealogia do Poder (ldem, 1986) propõem o resgate dos percursos de construção dos saberes, assim como a análise de como estes compõem relações de poder. A emergência de saberes é perceptível através de diversos vestígios discursivos (textos e imagens de diferentes fontes) de maneira não necessariamente organizada e programada (por isso a analogia com o método arqueológico). A análise das relações de poder permite compreender a emergência e a naturalização de determinados saberes, desta forma, identificar uma ordem discursiva hegemônica (esse mapeamento é chamado de genealogia). Cabe destacar que o saber, para Foucault (2004): "[...] pode estar em ficções, reflexões, narrativas, regulamentos institucionais, decisões políticas" (p. 205). Neste sentido, busca-se compreender os saberes que emergem nas Exposições do Império e nos Museus dos Descobrimentos e como eles estão articulados com relações de poder de gênero e raça. Inseridas nesta metodologia, as técnicas de recolha de dados foram: a pesquisa documental em fontes secundárias e a pesquisa de campo com observação direta e entrevistas (tendo como instrumentos o diário de campo e o roteiro semiestruturado).

O artigo inicia com uma discussão teórica e metodológica, avança para a pesquisa de campo nos Museus dos Descobrimentos do Porto e de Belmonte, adentra o universo das Exposições do Império Português através de pesquisa documental em fontes secundárias, e encerra com as considerações finais.

\section{Discussões teóricas e metodológicas}

\subsection{A Arque-genealogia: discursos e poder}

Teóricos sociais contemporâneos, como Pierre Bourdieu e Michel Foucault, levaram a compreensão da violência e do poder a dimensões subjetivas, demonstrando sua profundidade

\footnotetext{
' Destaca-se que a análise deste Museu está inserida em uma pesquisa maior que percorreu, no período de 2014 a 2016, cidades históricas do período colonial, do Brasil e de Portugal, para entender quais discursos emergem nestas cidades, sobretudo em seus museus, bem como compreender se estes discursos reproduzem racismos e sexismos. Esta pesquisa, intitulada "Narrativas Patrimoniais e Turísticas em Cidades Históricas: (des)(re)construções do lusotropicalismo no Brasil e em Portugal”, foi financiada pela CAPES e pelo CNPq, através da Chamada Pública n 43/ 2013, Código de Financiamento 001.
} 
e seus aspectos imateriais, porém, sem renunciar à compreensão da estrutura social. Nesta perspectiva, Bourdieu (2006) cunhou o conceito de poder simbólico, o qual: "é, com efeito, este poder invisível, o qual só pode ser exercido com a cumplicidade daqueles que não querem saber que lhe estão sujeitos ou mesmo que o exercem" (p. 7-8). Em "A Dominação Masculina", o autor argumenta que este poder simbólico é justamente uma das bases fundamentais de dominação dos homens sobre as mulheres.

Teóricas Feministas, como Anne-Marie DEUVREUX (2014), concordam com Bourdieu, no sentido de afirmar que existe um poder simbólico. No entanto, discordam da afirmação de Bourdieu sobre a "cumplicidade das vítimas". Para Deuvreux (2014), Bourdieu teve uma lucidez obstruída por não perceber as diferentes formas pelas quais as mulheres resistem a este poder simbólico que as inferioriza e as limita.

Concordando com as críticas feministas a Bourdieu, entende-se que as contribuições de Foucault sejam mais profícuas. A ideia de uma violência simbólica é entendida por Foucault (2004; 2008) através da análise dos discursos que são naturalizados como verdades em um exercício de poder, os quais produzem uma ordem discursiva, que cria papéis sociais, os quais interferem nas subjetivações. No entanto, para Foucault, esta subjetivação é sempre um ato de resistência (Gilles DELEUZE, 1998).

Para analisar discurso e poder, propõe-se a Arque-genealogia (FOUCAULT, 1986; 2004), a qual se baseia em um resgate da construção dos saberes e na análise de como estes compõem relações de poder. A emergência de saberes/discursos é perceptível através de diversos vestígios discursivos (falas, textos, imagens, disposições arquitetônicas) de maneira não necessariamente organizada e programada (por isso a analogia com o método arqueológico). Destaca-se este conceito ampliado de discurso (Alison LEE; Alan PETERSEN, 2015) que permitirá investigar as narrativas dos museus e exposições, incluindo imagens. A análise das relações de poder permite compreender a emergência e a naturalização de determinados saberes, assim como identificar uma ordem discursiva hegemônica (esse mapeamento é chamado de genealogia).

Neste sentido, pretende-se analisar os discursos da Exposição do Império Português e dos Museus dos Descobrimentos como vestígios de uma ordem discursiva imersa em relações de poder patriarcal, colonial e racista. Ainda segundo Foucault (1993; 1996), a sexualidade e a racialização são os principais dispositivos de poder da era moderna.

\subsection{O corpo colonial: interseccionalidade de gênero, raça e sexualidade}

Segundo Foucault (1996; 1993), raça e sexualidade são construções discursivas relacionadas com relações de poder que marcam de forma determinante a cultura ocidental moderna e contemporânea. O pensamento foucaultiano se alinha com a teoria feminista, a qual, desde O Segundo Sexo (1948), de Simone de BEAUVOIR (2009), afirma que ser mulher é uma construção social. Foucault se torna uma importante influência para os Estudos Feministas e Antirracistas. No entanto, o autor não desenvolveu uma perspectiva interseccionada entre estas relações de saber-poder: raça-gênero-sexualidade.

A discussão teórica e política da interseccionalidade emerge no final da década de 1970 , a partir do movimento de mulheres negras. Nos Estados Unidos da América, destaca-se Angela DAVIS (1982). No Brasil, evidencia-se o Manifesto das Mulheres Negras durante o Congresso de Mulheres Brasileiras, em 1975 (Kia CALDWELL, 2000). Não bastava pensar e lutar pela "mulher" no singular, tampouco pelo "negro".

Em uma breve retomada das principais discussões que permearam a emergência da teoria da interseccionalidade, é importante destacar as contribuições de Joan Scott (1986), que defende a utilização da categoria gênero. A abordagem de gênero aponta que as relações sociais e todos os âmbitos da vida são permeados pelas relações de gênero, que definem socialmente o que é "ser homem" e o que é "ser mulher". A autora empreende uma analogia entre os estudos de gênero, de classe e de raça, como análises das estruturas de poder; mas se esforça em construir uma teoria do gênero específica, mais do que em pensar na relação entre estas estruturas.

Judith BUTLER (2008) critica a divisão sexo biológico versus gênero social, presente, segundo a autora, na teoria do gênero, ao demonstrar que a sexualidade ocidental é construída a partir da norma heterossexual. A heterossexualidade compulsória "faz viver", produz homens e mulheres; ao mesmo tempo em que "deixa morrer" os homossexuais, transexuais e outras múltiplas formas de sexualidade. Nessa análise da matriz heterossexual, Butler demonstra que a sexualidade construída a partir do binário homem/mulher produz e naturaliza a existência de dois corpos, o masculino e o feminino. Butler (2008) questiona a abordagem sexo/gênero, na qual sexo é natural/biológico, e gênero é construído, demonstrando que essa suposta diferença biológica entre homens e mulheres também faz parte de uma construção discursiva do dispositivo da heterossexualidade. A autora demonstra que o corpo não é anterior ao discurso sobre o corpo; o corpo é uma construção cultural, permeada de relações de poder, limitada pelos marcadores sexuais (também construídos) como corpo feminino e masculino. 
Em uma análise semelhante, emergem as discussões sobre raça como construção social, interseccionada com a produção de uma sexualidade específica. Olívia CUNHA (2002) aproxima as análises de Foucault (sobre o biopoder) e as de Fanon (sobre raça, subjetivação e poder colonial), demonstrando que um dos mecanismos do biopoder (da racialização do negro e de sua inferiorização) é o discurso (produzido no período colonial) que constrói uma erotização dos negros. Segundo Fanon (1983, p. 153-154), o negro foi construído como símbolo do pecado, sendo que: "para a maioria dos brancos, o negro representa o instinto sexual" (FANON, 1983, p. 145).

Ao relacionar o dispositivo de gênero e sexualidade com o de racialização, as teorias feministas descoloniais destacam a intersecção na produção das duas essencializações sobre as mulheres. As mulheres brancas europeias são construídas como Marias/mães/esposas/virgens e as indígenas, negras ou mestiças das ex-colônias são construídas como Evas/pecadoras/prostitutas (Verena STOLKE, 2006). Raewyn CONNELL (1998) aponta que o colonialismo teve impacto na construção de uma ordem global de gênero, a qual construiu masculinidades diferentes e hierarquizadas entre homens da metrópole e homens das colônias, reforçou as assimetrias entre homens e mulheres nas colônias e entre metrópoles e colônias, fomentou violências contra as mulheres e criou um imaginário colonial relacionado ao erótico.

Através das discussões teóricas e políticas em torno da interseccionalidade entre gênero e outros demarcadores sociais, reconheceu-se que "mulher" não é uma categoria unitária (Avtar $\mathrm{BRAH}, 2006$ ). Tornou-se evidente a necessidade de compreender a racialização do gênero e emergiu o feminismo negro, terceiro-mundista, descolonial, latino-americano, entre outros (Lélia GONZALEZ, 1988; Elisa NASCIMENTO, 2003; bell HOOKS et al., 2004). A intersecção não é a simples sobreposição de diferentes subordinações, é uma discriminação interativa, uma discriminação específica (Kimberlé CRENSHAW, 2002).

Neste marco, emerge o conceito de corpo colonial. Lugones (2008), inserida na discussão sobre a colonialidade do poder (Aníbal QUIJANO, 2005) - a qual afirma que a principal marca da Modernidade é a criação do conceito de raça -, destaca a colonialidade do gênero, que marca o patriarcado moderno. Desta forma, o patriarcado não pode ser compreendido sem a análise do colonialismo. No mesmo sentido, McClintock (2010) afirma que a relação crucial entre gênero, sexualidade e imperialismo tem sido desconhecida e desprezada. Lugones (2008) destaca a violência sexual e estigmatização da sexualidade das mulheres não brancas durante o colonialismo (mulheres negras e indígenas escravizadas, entre os séculos XVI- XIX); bem como a manutenção da violência racista e sexista contra mulheres não brancas, devido à colonialidade do gênero. Nesta mesma linha, um artigo recente reforça a importância de articular a discussão decolonial e a categoria gênero (Camilla GOMES, 2018).

As discussões feministas descoloniais recuperam Fanon e sua analítica sobre o corpo colonial. O corpo colonial é um corpo construído como alvo da opressão dos colonizadores, em uma intersecção de raça, gênero, sexualidade e classe (exploração do trabalho). O corpo colonial é, sobretudo, um corpo visto como disponível. Oto (2006; 2013) destaca que o conceito fanoniano de corpo colonial explicita que a opressão se dá através do próprio corpo, por meio de uma animalização do corpo do outro, o que implica também a resistência dos sujeitos que reinventam a si mesmos. No mesmo sentido, McClintock (2010) aborda o "couro imperial", ao relacionar, de forma intrínseca, gênero, raça, sexualidade, classe e poder imperial, no contexto do império britânico; ao mesmo tempo em que ressalta as múltiplas formas de resistência (seja a dissimulação, negociação, revolta, recusa, cumplicidade). Laura LÓPEZ (2015) demonstra a importância da categoria corpo colonial para compreender as lutas das mulheres negras na América Latina.

Destaca-se que o conceito de raça é utilizado como construção social relacionada ao histórico de racismo (FANON, 1983; Etine BALIBAR; Immanuel WALLERSTEIN 1988; Kabengele MUNANGA, 1999) e a perspectiva epistemológica descolonial (QUIJANO, 2005; Walter MIGNOLO; Ramón GROSFOGUEL, 2008).

Ou seja, o que os/as diferentes autores/as citados/as demonstram é que raça, gênero e corpo (ser homem/ser mulher, ser negro/ser branco) são construções sociais, discursivas e performáticas, cujas existências ocorrem em meio a relações de poder - não são definições meramente biológicas. Esta discussão teórica irá contribuir para a análise sobre como as Exposições do Império Português e os Museus dos Descobrimentos constroem discursivamente os corpos, em articulações de raça e gênero. Buscar-se-á perceber como o corpo aparece nessas narrativas.

\subsection{Os Museus na construção de uma ordem discursiva}

A historiadora feminista Michelle Perrot ressaltou o quanto a escrita da história reproduz silêncios sobre o passado e, assim, relações de poder no presente (Joana PEDRO, 2003). Também Maurice HALBWACHS (1990) demonstrou que a memória é uma construção social. Michael POLLAK (1989) destacou que a memória coletiva deve ser entendida a partir de sua função social, tendo em vista os processos arbitrários de produção desta memória. No mesmo sentido, Mário CHAGAS (2003) afirma que: "o caráter seletivo da memória implica o reconhecimento da sua vulnerabilidade 
à ação política de eleger, reeleger, subtrair, adicionar, excluir e incluir fragmentos no campo do memorável" (p. 141).

Neste âmbito de disputas simbólicas que constroem a memória coletiva, a história contada nos Museus também compõe a Ordem Discursiva - ou o universo enunciativo das verdades sobre o passado - marcada por relações de poder desiguais entre aqueles que podem ou não enunciar.

De forma breve, a partir de Camilo VASCONCELLOS (2006), pode-se destacar que a história dos Museus remonta à Grécia Antiga, onde foram criadas as "Casas das Musas" como locais dedicados à memória, ao saber e à contemplação do belo. Em Roma estes espaços ganharam contornos políticos de visibilidade do poder, com a formação das coleções dos imperadores, com objetos oriundos de diferentes partes do Império Romano. Na ldade Média, o Vaticano manteve a tradição das coleções de objetos de diferentes regiões, bem como coleções de arte. Na ldade Moderna, com o Renascimento e a Expansão Ultramarina, os Reis Absolutistas aprofundam a tradição das coleções privadas como símbolos de poder, dividindo-as em: (a) Gabinetes de Curiosidades do Novo Mundo, (b) Objetos Antigos de Origem Europeia e (c) Obras de Arte. Estas coleções darão origem, na ldade Contemporânea, respectivamente, aos: (a) Museus da História Natural, (b) Museus Históricos e (c) Museus de Belas Artes. Esta transformação, ocorrida na ldade Contemporânea, inicia-se com a ideia de abertura das coleções dos reis ao público em geral, durante a Revolução Francesa, no final do século XVIII, com seus ideais de "liberdade, igualdade e fraternidade". É neste momento que os museus se tornam públicos. Ao longo do século XIX e início do século XX foram surgindo novos Museus públicos (Timothy MASON, 2004), inspirados pelo Museu do Louvre, aberto ao público após a Revolução Francesa de 1789-1799.

Os museus ganharam importância simbólica na sociedade, mas permaneceram com narrativas associadas à história tradicional, tendo sido alvo de protestos, como no já mencionado caso das Sufragistas inglesas. A partir da década de 1960, com as diferentes contestações sociais, fortaleceram-se as críticas aos museus, sobretudo a seu elitismo. Mesmo depois da abertura ao público, promovida desde a Revolução Francesa, os museus teriam permanecido com uma barreira simbólica, afastando as classes populares enquanto público, bem como silenciando suas histórias. Destas críticas emergiram inovações, como Ecomuseus, museus voltados à cultura popular, indígena, afro, museus interativos com uso de tecnologia, entre outros. No entanto, estes ainda são minoria com relação aos museus tradicionais (VASCONCELLOS, 2006).

Além de serem numericamente poucos, os museus voltados para os grupos historicamente marginalizados nem sempre os representam de maneira adequada. Conforme demonstra o trabalho de Jéssica HIPÓLITO (2017) sobre museus cariocas, nem todos os museus com foco na cultura negra possuem um discurso em diálogo com o que propõe o movimento negro; alguns reforçam estereótipos, preconceitos, subalternidade e o olhar do colonizador. No que tange ao gênero, alguns museus portugueses também reforçam imagens tradicionais sobre as mulheres (mãe, esposa, amante), como analisado por Aida RECHENA (2011).

Atualmente, os museus estão inseridos na Cultura da Memória (Andreas HUYSSEN, 2000), sendo o principal atrativo do turismo cultural, possibilitando que milhões de pessoas se interessem por monumentos históricos. No entanto, este interesse se deu mediado pelos valores capitalistas (Françoise CHOAY, 2001). Nesta Cultura da Memória, os museus jogam um papel importante nas relações de poder do capitalismo, que se associam com as relações de poder patriarcais e racistas nas quais os museus já estavam imersos.

Neste mesmo sentido, Reinaldo DIAS (2006) destaca que o turismo cultural pode ser um promotor de violência simbólica, no sentido bourdiesiano, ao valorizar apenas a cultura de determinados grupos sociais (sobretudo de origem europeia). Do ponto de vista foucaultiano, é interessante destacar a emergência de turismo e museus contra-hegemônicos, ou seja, resistências através do turismo e dos museus, como, por exemplo: o caso do Turismo de Base Comunitária em Quilombos (GOMES et al. , 2016); o caso de itinerários turísticos com enfoque na história e na cultura afro-brasileira e das mulheres; ${ }^{2}$ o caso do Museu llè Ohun Lailai, do Terreiro llè Asè Opo Àfonjá, em Salvador (GOMES, 2014) - da mesma forma que Nead (1992) ressaltou a arte feminista. Neste cenário de disputas discursivas nos museus, nos patrimônios e no turismo reforça-se a importância de analisar os Museus dos Descobrimentos Portugueses.

\section{2 o corpo descoberto e o corpo colonial nos Museus dos Descobrimentos Portugueses}

Durante os anos que vivi em Portugal, muitas vezes me deparei com a ideia dos portugueses de que a Colonização e os Descobrimentos são fatos históricos distintos. Algumas vezes entrei em discussão contra essa ideia. Para uma brasileira, esses fatos históricos parecem

\footnotetext{
${ }^{2}$ A autora está orientando a dissertação de mestrado de Laise Maria da Silva sobre este tema, intitulada: "À margem do Esquecimento: Narrativas sobre os Negros e Negras em Itinerários Turísticos de Penedo-AL", em breve disponível para leitura.
} 
indissociáveis. Hoje, ao realizar a pesquisa no Museu dos Descobrimentos do Porto, essa ideia fez mais sentido, ou, ao menos, fui capaz de entendê-la melhor, ao ter como foco a análise desse discurso (Mariana Selister Gomes. Trecho do Diário de Campo, nov. 2014).

Este trecho do Diário de Campo evidencia algo muito repetido pelos diretores e educadores dos museus estudados: "os museus exaltam os Descobrimentos, que são um orgulho para o povo português, mas não o Colonialismo, que veio depois" (Educador do Museu e Parque Temático dos Descobrimentos do Porto). O educador ainda destacou: "os brasileiros que nos visitam sempre perguntam da escravidão, mas esse não é o tema do Museu". Ao que parece, há uma tentativa de dobra discursiva por parte dos museus estudados, uma dobra que seria capaz de enaltecer os Descobrimentos e esquivar-se da crítica ao Colonialismo e ao Luso-tropicalismo.

Neste artigo, o foco da análise está no corpo, entendido como uma construção social, discursiva e performática, imersa em relações de poder, conforme as perspectivas teóricas já apresentadas. A seguir, portanto, abordar-se-á como o corpo, atravessado por raça, gênero e sexualidade, aparece nas narrativas dos Museus dos Descobrimentos Portugueses, tendo como reflexão a possibilidade - ou não - de dissociação entre um corpo descoberto e um corpo colonial. A seguir, buscar-se-á compreender as narrativas do Império Português sobre o corpo, para, através de uma arque-genealogia, refletir sobre as relações de saber-poder nos discursos do presente. Através da Análise dos Discursos que emergem sobre o corpo nestes museus e nestas exposições, buscar-se-á evidenciar se há ou não diferença entre um corpo dos descobrimentos e um corpo do colonialismo, a fim de compreender as (re)(des)construções do corpo colonial. Em novembro de 2014 foi realizada a pesquisa de campo no Museu e Parque Temático dos Descobrimentos (Porto) e no Museu dos Descobrimentos (Belmonte). ${ }^{3}$

\subsection{Museu dos Descobrimentos de Belmonte}

Belmonte é um pequeno município português, localizado na região da Serra da Estrela, pertencente à Rota Turística Aldeias Históricas. Localiza-se no alto de uma colina e possui construções em pedra, que remontam à Idade Média. A família Cabral era a proprietária do Castelo e de suas terras, sendo provável que Pedro Álvares Cabral tenha nascido lá.

O Museu dos Descobrimentos de Belmonte foi inaugurado em abril de 2009, no mesmo mês em que Pedro Álvares Cabral chegou ao Brasil. Segundo o criador do Museu, historiador e proprietário de uma empresa que desenvolve projetos e produtos culturais, a iniciativa foi da gestão pública municipal de Belmonte, com objetivo de atrair turistas, para dinamizar a economia do município. O foco do museu é a figura histórica de Cabral e seus feitos, principalmente, a descoberta do Brasil.

O Museu possui pouco acervo material, composto de vestígios arqueológicos da Família Cabral. Segundo seu criador, o maior objetivo é contar uma história e não preservar acervos. Para isto, faz uso de cenários e tecnologias. A primeira sala é dedicada à história de Belmonte e da família Cabral. A seguir está a sala dedicada a Lisboa da época dos descobrimentos, onde o visitante pode interagir e descobrir o que ocorria na cidade na época. Em seguida, há uma sala voltada à vida a bordo das caravelas, com telas interativas, em um cenário que simula uma caravela. Ao destacar a vida a bordo, é mencionado que essa prática era proibida às mulheres.

A seguir o visitante passa por um túnel, com projeções de $180^{\circ}$, onde se sente na viagem e é conduzido pela Carta de Pero Vaz de Caminha. A partir de então, as salas são dedicadas ao Brasil. A primeira aborda o contato com índios. Cabe destacar uma frase da entrevista com o criador do Museu, pois, quando ele descreve essa sala, menciona que ela é dedicada à história "dos primeiros portugueses que foram largados no Brasil para se cruzar com as tribos e ficar". Ao descrever os indígenas, o painel expositivo menciona: "embora em estágios primitivos de desenvolvimento, os índios dão lição ao mundo desenvolvido de preservação dos ecossistemas". Fica evidente uma tentativa de valorização dos indígenas no que tange ao destaque dado à preservação ambiental (o que é uma dobra discursiva). Mas se mantém o olhar colonial sobre os indígenas (narrados como primitivos), bem como a ideia de disponibilidade sexual dos corpos das mulheres indígenas (no discurso de que os portugueses que iriam "cruzar" com as indígenas), ou seja, reproduz-se a perspectiva do corpo colonial.

A seguir há uma sala dedicada à biodiversidade do Brasil, com imagens, sons e informações sobre a flora e a fauna, reforçando um imaginário de natureza selvagem, o qual também compõe o repertório discursivo do colonialismo.

Em seguida, há uma sala chamada "Terra Brasilis", com telas multimídia onde aparecem personagens, imagens antigas e atuais, e explicações sobre o país. Referente aos indígenas, é mencionada a carta de Pero Vaz de Caminha e é destacado que "são homens pardos que andam nus, sem vergonha", em uma reprodução do corpo desnudo como símbolo de inferioridade,

\footnotetext{
${ }^{3}$ Pesquisa de campo com apoio e financiamento da Coordenação de Aperfeiçoamento de Pessoal de Nível Superior - Brasil (CAPES) - Código de Financiamento 001, por meio da Chamada Pública n 43/2013.
} 
ou seja, do corpo colonial. Isto pode ser percebido, sobretudo, em comparação aos portugueses, que são mencionados pela língua portuguesa e pela civilização. Sobre os negros, é mencionada a capoeira, com exibição de corpos seminus, novamente reforçando o imaginário de corpo colonial. A miscigenação é apresentada como raiz da nacionalidade. Fica evidente a visão hegemônica, reforçando a associação dos indígenas com a nudez, dos negros com o corpo através da capoeira, dos brancos com a intelectualidade. Ou seja, é enfatizada a animalização de indígenas e negros, em uma reconstrução do corpo colonial.

A próxima sala aborda a escravatura. Nas palavras do criador do Museu:

E temos depois uma sala, que fica meio escondida, com a porta de uma cela, vamos chamar assim, que fica sempre aberta, que significa a libertação dos escravos. Temos uma aplicação sonora, a qual se trata de um misto daquilo que foram as amarguras que eles sofreram, dos gritos e das torturas, mas sobretudo também temos outra questão muito importante que temos também o som da capoeira que é o som também da libertação (Criador do Museu, em entrevista, nov. 2014).

Apesar de ter uma preocupação com a ideia de liberdade, há uma naturalização dos corpos coloniais escravizados nas imagens e textos. Os textos nos painéis explicativos sobre escravidão naturalizam a versão eurocêntrica da História, onde os europeus são, em grande medida, desculpabilizados pelo tráfico, enfatizando-se a já existência de escravidão na América e o papel dos negros no tráfico. Lê-se: "Hoje sabemos que a escravidão já existia na América antes da chegada dos Europeus [...] Eram os negros que capturavam os negros para depois venderem nas praias aos comerciantes europeus".

Essa versão da história tem sido extremamente criticada por inúmeros historiadores. O fato histórico consensual é que jamais houve um comércio de seres humanos escravizados nas proporções daquele provocado pelo colonialismo europeu. Ao mesmo tempo em que o painel reconhece isto, coloca a responsabilidade nos próprios negros e nas guerras internas. No entanto, a escravidão colonial foi justificada pela cor da pele (não por guerras ou dívidas como escravidões anteriores), por isto sua imensa proporção e consequências até hoje (BALIBAR; WALLERSTEIN, 1988). No painel "Razões da Escravatura" permanece a naturalização. A primeira frase afirma: "O primeiro fator da escravização do negro no Brasil foi o açúcar". Não é questionado o modelo de colonização. É naturalizado, como se fosse a única alternativa de colonização: escravidão e latifúndio. Ao ser questionado acerca das diferentes visões sobre a escravidão, o criador do Museu enfatizou: "nós não trazemos esse olhar crítico". Quando não há uma crítica explícita, acaba-se por reproduzir o discurso hegemônico colonial.

Em seguida, há uma sala dedicada aos vários povos que migraram para o Brasil. A seguir, há uma sala voltada à Língua Portuguesa. Após esta sala, há uma escada com uma linha do tempo da história do Brasil. Nesta linha há um erro: a Ditadura Militar é apresentada como de 1960-1985, quando ocorreu de 1964-1985.

Quando se chega ao piso superior, encontra-se o foco no Brasil atual. Neste momento, o Museu destaca a música e alguns produtos (como o café, o açúcar, a cachaça e o petróleo). A última sala é dedicada à identidade brasileira, com um vídeo com imagens e sons do Brasil. Ao falar desta sala, o entrevistado destaca: "carnaval, futebol, dança e tribos indígenas". A exposição termina com um vídeo composto por várias telas (tamanho aproximado de 4 metros por 2 metros) passando imagens diferentes simultaneamente e às vezes compondo uma única imagem grande. Há cenas que parecem clássicas de turismo sexual no Nordeste (mulheres negras jovens com homens brancos velhos). Há uma imagem grande de uma mulher nua no carnaval do Rio de Janeiro. Há imagens de bundas de fio dental na praia. Há frases: "nossa verdade é a mistura"; "o chamego brasileiro". Há muitas informações sobre a cultura brasileira, mas sem o uso da palavra cultura, nem folclore, nem patrimônio cultural - as palavras usadas são musicalidade e identidade. Tanto na sala sobre musicalidade quanto na sala final há corpos de mulheres nuas como sínteses do Brasil.

Destaca-se que as mulheres nuas apresentadas pelo Museu são tipicamente brasileiras aos olhos dos portugueses. Isto porque as brasileiras são consideradas como uma raça mestiça em Portugal (mesmo aquelas que aos olhos dos brasileiros possam ser brancas), sendo esta uma forma de racialização das brasileiras em Portugal, marcada pela colonialidade, como argumenta Gomes (2013). Neste museu, descobrimentos e colonização fundem-se em um mesmo olhar eurocêntrico. Apesar de o nome do museu enfocar os descobrimentos, grande parte das salas é dedicada ao Brasil Colônia, Império e República. Há uma continuidade entre Descobrimentos, Colonização e atualidade. Os indígenas são apresentados com corpos nus e inferiorizados como primitivos. Os negros são descritos através da escravidão naturalizada. A identidade brasileira é apresentada em continuidade à mestiçagem do período colonial e é sintetizada através do corpo da mulher brasileira nua: um corpo colonial disponível. Relações de poder de gênero e raça se reproduzem nos discursos deste Museu, com essencialização e inferiorização de negros, indígenas e mulheres. 


\subsection{Museu e Parque Temático dos Descobrimentos do Porto}

A cidade do Porto está localizada às margens do Rio Douro, ao norte de Portugal. A imagem da cidade está relacionada à história do Vinho do Porto, que, por sua vez, situa-se no período do Império Português, quando a bebida se tornou um produto valorizado no mundo. A cidade hoje é um grande polo de atração de turistas. Em função do turismo, mas também focando o público escolar, um investidor privado, com apoio de algumas empresas de turismo, financiou o Museu e Parque Temático dos Descobrimentos (conforme informações prestadas por uma das diretoras), localizado às margens do Douro, nos antigos armazéns do porto. O Museu e Parque Temático é um espaço diferente de um museu tradicional. Segundo uma de suas diretoras, a equipe decidiu reforçar seu nome como Museu (por preservar uma memória, apesar de não conter acervo material) e apresentar-se também como Parque Temático (pelo caráter lúdico).

O espaço é constituído de vários cenários e faz uso de tecnologias para narrar a história dos descobrimentos portugueses. Em cada sala há um educador vestido como um personagem da época, que conta a história. O espaço recebe muitos visitantes, cerca de 600 por dia.

Os visitantes são recebidos por Infante Dom Henriques, através de um áudio no qual o personagem destaca que o visitante irá conhecer a "odisseia que mudaria a história do mundo [...] promovendo um encontro de culturas único e criando a globalização". Fica claro o enfoque nos Descobrimentos de uma maneira positiva. A primeira sala é dedicada às embarcações, com maquetes e monitores interativos. Enfatiza-se o papel também dos franceses, holandeses, corsários e piratas ingleses. Menciona-se o papel dos chineses nos instrumentos náuticos.

Os portugueses deram "Mundos ao Mundo" é o nome da segunda sala. Nela há painéis interativos sobre os personagens das navegações, a vida a bordo, os mitos e histórias, e há também globos interativos sobre as rotas marítimas. É mencionado que as mulheres eram proibidas de fazerem parte das embarcações. Neste museu, porém, destaca-se que algumas se vestiram de homens para ir: "Muitas vezes algumas mulheres mais aventureiras subiam a bordo disfarçadas de homem, cortavam o cabelo, engrossavam a voz quando tinham que falar ou pouco falavam, embora fosse terminantemente proibido". Nos Mitos e Histórias é citada a Catarina Pires, Flor de Miragaia, que seria uma mulher do povo que se casou com Garcia de Sá, que se tornou Governador da Índia, tendo ela viajado com ele para além-mar. Neste museu, com relação ao anterior, é dado mais destaque às mulheres, que são apresentadas de forma ativa.

Ainda nos Mitos e Histórias, é contada a "Estória do Caramuro", que seria um integrante de uma "expedição à Terra de Vera Cruz", que teve seu navio naufragado na Bahia de Todos os Santos, ocasionando a morte de muitos tripulantes. Aqueles que conseguiram nadar teriam sido "abatidos, esquartejados, assados e comidos pelos índios Tupinambás", com exceção de Diogo Álvares Correia, que teria sido poupado por "ser muito magro" e teria ganhado a confiança dos índios, ganhando o nome de Caramuro e recebido a filha do chefe tubinambá, Paraguaçu, e se interessado também por Moema. "Como a poligamia fazia parte da rotina desta tribo, Caramuro pôde relacionar-se com as duas esbeltas índias". Ele teria se tornado um importante intermediador no comércio de pau-brasil. Em certa ocasião teria viajado para França, levando Paraguaçu, onde ela teria sido batizada e eles teriam tido um casamento católico e regressado ao Brasil. Nesta parte, é reforçada a ideia de exotismo indígena, no entanto, esta história aparece entre os mitos, de forma lúdica, e com um final feliz, conforme a narrativa. Não aparecem palavras como selvagens e primitivos.

Há uma sala que simula o porão de uma embarcação, com homens em cera de tamanho real, um hipopótamo em cera, vários produtos e equipamentos que eles usavam. Depois há uma sala sobre a forma de construir as embarcações, onde é mencionado o papel das mulheres nesta tarefa, especialmente na costura, na cidade do Porto.

A parte que mais chama atenção dos visitantes é "a viagem". Como em um parque de diversões, o visitante embarca em uma "minicaravela", que desliza sob um trilho escondido embaixo da água e parte para as descobertas, com um áudio-guia que narra as viagens dos portugueses pelo mundo. A viagem parte da Torre de Belém e vai sendo conduzida por várias partes do mundo aonde os portugueses chegaram. A produção dos cenários tem bastante qualidade. Há personagens em cera com tamanho real, simulação de temperatura e clima, animais em cera e alguns animais reais (como um tucano). A viagem passa pelo Cabo das Tormentas, pela África, por florestas tropicais, pela China, Índia, Timor, Japão e Brasil. Em cada destino, a cultura local é representada, além do encontro com os portugueses. No caso do Brasil, a cena apresentada é a da primeira missa, onde aparecem os índios com curiosidade, espiando atrás de uma árvore.

Nestes cenários, as mulheres são mostradas em suas culturas e de forma ativa (com trajes típicos, trabalhando, cuidando dos filhos), com um certo exotismo, porém, não com uma ideia de submissão ao europeu, nem como disponíveis sexualmente. Destaca-se que as coordenadoras do Museu são em sua maioria mulheres.

Na cenografia parece haver um foco no corpo descoberto, marcado pela curiosidade mútua, sem o elemento da submissão do corpo colonial; mas, ainda assim, é um corpo exposto. No 
entanto, representa uma dobra discursiva com relação ao corpo colonial, bem como um tensionamento nas relações de poder. O foco da narrativa é a Descoberta e o momento do encontro entre as culturas diferentes. Ainda que a ideia de Descoberta seja eurocêntrica e tenha sido usada, muitas vezes, para silenciar a crítica ao colonialismo, percebe-se uma perspectiva diferente da ideia de submissão presente nas narrativas naturalizadas da Colonização. Há, portanto, uma tentativa mais evidente de dissociar Descobrimentos de Colonização no Museu e Parque Temático dos Descobrimentos do Porto, a qual é bem construída em grande parte da narrativa do Museu, quando o enfoque são as navegações, a vida nas caravelas, as rotas marítimas e o encontro entre as diferentes culturas. Neste Museu não há mulheres nuas como símbolo do mundo que o português criou nos trópicos, ao contrário do Museu dos Descobrimentos de Belmonte. O fato de não haver mulheres nuas neste Museu merece ser destacado como forma de dobra discursiva e tensionamento nas relações de poder, sobretudo tendo em vista a análise de Nead (1992) que demonstra a histórica associação entre patriarcado e nudez das mulheres em exposições (mesmo que a autora enfoque obras de arte e aqui o foco seja museus históricos, a reflexão sobre os corpos desnudos expostos é similar).

A seguir buscar-se-á mapear a genealogia da construção do corpo nu como símbolo do império e das relações de poder de raça e gênero.

\section{O Luso-Tropicalismo e o corpo colonial nas exposições do Império Português}

Um dos exemplos mais discutidos e evidentes da construção do corpo colonial foi trazido por McClintock (2010), na análise do Império Britânico. Dentre suas investigações destaca-se o caso de Saartjie Baartman (1789-1815), uma mulher sul-africana que fora levada à Europa para ser exibida como atração em espetáculos circenses, sob o nome de "Vênus Hotentote". Seu corpo fora exibido como símbolo da sexualidade primitiva (McCLINTOCK, 2010, p. 74). Baartman foi exibida na Europa por cinco anos. Depois dela, outras mulheres africanas foram trazidas, não só para espetáculos circenses, mas também para serem exibidas nuas em bailes da nobreza e da burguesia para um público voyeur (idem, ibidem). O caso da Vênus Hotentote foi um exemplo contundente do que McClintock (2010) chamou de Couro Imperial - da articulação de violências, de gênero, raça e sexualidade impetradas sobre, através e a partir dos corpos das mulheres colonizadas.

A exposição pública, erotizada e exotizada do corpo da mulher africana também ocorreu em Portugal. Conforme Manuela SANCHES (2012): "Portugal não deixa de participar, mesmo neste 'império de papel', não só da violência colonial, como nos processos de instrumentalização do saber em nome da missão civilizadora inerente a esse projeto de hegemonia europeia" (p. 197).

Leonor MARTINS (2012) analisa as imagens do colonialismo português na imprensa periódica, de 1875 até 1940, destacando que ela publicava estas imagens com objetivo de construir uma identidade nacional portuguesa ancorada na missão de "descobrir, colonizar, civilizar" (idem, p. 149-150). Segundo a autora (idem, p. 55), a seminudez das mulheres africanas foi um dos tópicos mais persistentes desta imprensa colonial.

O exemplo que este artigo objetiva destacar é a presença de mulheres africanas seminuas exibidas ao público na Exposição Colonial de 1934 e na Exposição do Mundo Português de 1940. Infelizmente, Portugal também teve "sua Saartije Baartman". Rosinha fora trazida da Guiné para ser exposta ao público, representando "os indígenas" das colônias, sobretudo a condição primitiva e selvagem dos guineenses, os quais Portugal ainda não teria tido tempo de corrigir e civilizar devido ao domínio colonial recente (MARTINS, 2012, p. 172). A autora relata que visitantes tentaram beijar Rosinha e ficavam observando as guineenses durante a noite. Além da exploração de seu corpo como objeto de uma exposição oficial, sua imagem, com seios desnudos, foi intensamente reproduzida pela imprensa, sendo, inclusive, capa da revista Civilização dedicada à Exposição Colonial.

No caso da exposição de 1940, o cartaz era composto por mulheres de várias partes do império, incluindo uma mulher negra nua. Percebe-se que há uma mudança no título: de "Exposição Colonial" para "Exposição do Mundo Português". Já há uma nova leitura do colonialismo, pela narrativa luso-tropical que será abordada a seguir. Mas o corpo nu da mulher negra, o corpo colonial, permanece como símbolo.

Conforme Ana RUIVO (2010), "o corpo do outro" foi um dos elementos que mais causou reações nos exploradores coloniais. As descrições dos indígenas brasileiros e de seus costumes, especialmente dos hábitos relacionados ao corpo, foram as principais temáticas nos relatos dos portugueses na segunda metade do século XVI. Os indígenas eram descritos como bárbaros e seus corpos construídos como impuros e pecadores. Margareth GONÇALVES (2005) também analisa relatos dos viajantes do período colonial, demonstrando o quanto este discurso de barbárie, pecado, sexualidade exacerbada estava presente nas narrativas sobre os povos das colônias. O que se pretende destacar é que estes discursos não estavam presentes apenas na literatura de viagem, de alcance de poucos letrados, mas também nas exposições em praça pública, até o século XX. 
Conforme Rosana NASCIMENTO (2008), a Exposição do Mundo Português foi um momento de afirmação da identidade nacional portuguesa através da valorização das glórias do passado e da expansão portuguesa no mundo. A autora analisa a participação do Brasil na referida exposição e conclui que o Brasil é apresentado com ênfase no período colonial e como parte de Portugal como um exemplo de sucesso do colonialismo português (idem).

Neste contexto, conforme Castelo (1998), Gilberto Freyre recupera o ideário romântico dos relatos dos viajantes, utilizando-os como fonte histórica, para escrever uma história do Brasil Colônia, a qual funda o mito luso-tropical, apoiado por ambos os regimes ditatoriais daquele momento (o Estado Novo de Vargas e o de Salazar). A autora (1998) define o luso-tropicalismo como "o modo português de estar no mundo". A mesma ideologia é definida como o "mito da democracia racial" ou "mestiçagem" no Brasil (MUNANGA, 1999). Poder-se-ia afirmar que o luso-tropicalismo consiste em uma ordem discursiva, a qual argumenta que os portugueses se misturaram sexualmente com as mulheres negras e indígenas, fundando uma civilização não racista no Brasil. Esta crença torna-se o elemento central da identidade nacional dos dois países - sendo o corpo (colonial) das mulheres negras e indígenas o centro dessa narrativa.

Conforme Castelo (1998), Portugal assume a teoria de Gilberto Freyre, sendo a principal ideologia do colonialismo português em África no século XX. António de Oliveira Salazar, que instituiu a ditadura do Estado Novo em 1933 e foi Primeiro-Ministro de 1932 até 1968, convocou Freyre para ser ideólogo de seu regime. Portugal conservava as colônias africanas difundindo a ideia de que era um colonialismo brando e benevolente. Conforme Almeida (2000): "debaixo do discurso democrático da mestiçagem, está latente o discurso hierárquico do branqueamento" (p. 191).

Ainda de acordo com Almeida (2000): "em grande medida, os discursos sobre miscigenação e mestiçagem demonstraram um pendor ideológico para o mascaramento de relações de poder desigual e de dominação. Serviram também como elementos centrais de narrativas nacionais, imperiais e coloniais" (p. 185). Para Castelo (1998), o luso-tropicalismo pode ser entendido como uma ideologia: "de facto, a doutrina de Freyre sustenta-se numa argumentação supostamente científica e obtém, graças fundamentalmente à propaganda salazarista, uma credibilidade excessiva" (p. 41).

Sustentado pelas relações de poder, sobretudo de gênero e raça, o luso-tropicalismo se tornou a ordem discursiva hegemônica em Portugal e no Brasil. Esse ideário foi exaltado nas Exposições do Império e o corpo colonial foi a síntese dessa narrativa.

No entanto, segundo Castelo (1998): "[...] o caráter científico do luso-tropicalismo foi desde cedo questionado, não só por activistas dos movimentos africanos de libertação, como por historiadores, antropólogos e outros investigadores sociais" (p. 41). No contexto brasileiro, esta hegemonia também não ocorreu sem críticas, as quais continuam atualmente. Os contradiscursos emergiram em movimentos sociais e em discursos acadêmicos.

Conforme Nascimento (2003), na década de 1940 se destacam o Teatro Experimental do Negro e o Jornal O Quilombo, ambos com a participação de Abdias do Nascimento. Na década de 1950, a Organização das Nações Unidas para a Educação, Ciência e Cultura (UNESCO) financiou uma investigação sobre as relações raciais no Brasil. O objetivo era apresentar ao mundo uma experiência bem-sucedida de relações raciais, conforme narrada pela obra de Freyre, que já possuía impacto mundial. Intelectuais importantes, como Florestan Fernandes, participaram do projeto, o qual levantou dados das condições de vida de negros e brancos e também analisou aspectos mais sutis do racismo. Conforme Thomas SKIDMORE (1989), o Projeto da UNESCO frustrou suas expectativas iniciais, acabando por evidenciar o racismo no Brasil. A partir daí muitas pesquisas demonstraram a presença do racismo no Brasil e analisaram o mito da democracia racial (Antônio GUIMARÃES, 2005; MUNANGA, 1999). No entanto, apesar das críticas, o luso-tropicalismo permanece no Brasil e em Portugal. Vive-se hoje um cenário de disputas discursivas sobre este passado colonial.

\section{Considerações finais}

No decorrer deste artigo, demonstrou-se que a memória sobre o passado colonial português foi marcada por narrativas que exaltaram o colonialismo e pouco criticaram as violências deste período, silenciando, sobretudo, a violência sexual contra mulheres negras e indígenas. Esse discurso hegemônico, entendido como luso-tropicalista, ou mito da democracia racial, começou a ser questionado a partir da segunda metade do século XX. Atualmente, há uma disputa pública em torno dessa memória, com debates sobre museus e monumentos.

Neste âmbito de disputas simbólicas, este artigo analisou os Museus dos Descobrimentos Portugueses (localizados no Porto e em Belmonte), buscando perceber como eles (des)(re)constroem narrativas em torno do corpo colonial, em comparação com narrativas das Exposições do Império Português. Após analisar separadamente cada discurso, chega-se a um quadro-síntese comparativo (Imagem 1), em uma tentativa de análise arque-genealógica, de inspiração foucaultiana, buscando perceber as continuidades e rupturas discursivas. 
Imagem 1: Quadro Síntese - Comparação entre os Discursos Expográficos

\begin{tabular}{|l|c|c|c|c|}
\cline { 2 - 5 } \multicolumn{1}{c|}{} & \multicolumn{4}{c|}{ Espaços Expográficos } \\
\cline { 2 - 5 } \multicolumn{1}{c|}{} & Museus dos Descobrimentos & \multicolumn{1}{c|}{ Exposições do Império } \\
\cline { 2 - 5 } \multicolumn{1}{c|}{$\begin{array}{c}\text { Porto } \\
\text { Elementos discursivos } \\
\text { em torno do corpo }\end{array}$} & \multicolumn{4}{c|}{} \\
\hline Selvagem/Primitivo & & $\mathrm{X}$ & $\mathrm{X}$ & $\mathrm{X}$ \\
\hline Subjugado & & $\mathrm{X}$ & $\mathrm{X}$ & $\mathrm{X}$ \\
\hline Disponivel & & $\mathrm{X}$ & $\mathrm{X}$ & $\mathrm{X}$ \\
\hline Exótico & $\mathrm{X}$ & $\mathrm{X}$ & $\mathrm{X}$ & $\mathrm{X}$ \\
\hline Nu & & $\mathrm{X}$ & $\mathrm{X}$ & $\mathrm{X}$ \\
\hline Culturas diferentes & $\mathrm{X}$ & & & \\
\hline
\end{tabular}

Elaboração: Mariana Selister Gomes.

\#PraCegoVer Na imagem, aparece um Quadro em que, no eixo x, estão identificados os espaços expográficos e, no eixo y, estão identificados os elementos discursivos em torno do corpo. No cruzamento entre os eixos aparece o seguinte: (1) Museu dos Descobrimentos do Porto, em que aparecem os elementos exótico e culturas diferentes; (2) No Museu dos Descobrimentos de Belmonte aparecem os elementos selvagem/primitivo, subjugado, disponível, exótico e nu; não aparece o elemento culturas diferentes; (3) Nas Exposições do Império de 1934 e de 1940, aparecem os elementos selvagem/primitivo, subjugado, disponível, exótico e nu; não aparece o elemento culturas diferentes.

Percebe-se que na primeira metade do século XX, momento das Exposições do Império, era possível (pelas relações de poder coloniais) exibir mulheres das colônias nuas, como partes da glória do império português e, ao mesmo tempo, afirmar-se como uma "democracia racial", como um império supostamente não racista. Já neste início de século XXI, o Movimento Negro e discursos intelectuais contra-hegemônicos conseguiram impor uma crítica às violências do período colonial, provocando tensionamentos nas relações de poder e rupturas discursivas.

Estas rupturas, ou dobras, podem ser percebidas no Museu e Parque Temático dos Descobrimentos, no Porto, onde há uma dissociação entre Descobrimentos e Colonização. Nessa dissociação, o corpo colonial não aparece em seus elementos de subjugação e disponibilidade; emerge um corpo descoberto, que também é um corpo exposto, mas não é um corpo subjugado, é um corpo marcado pela curiosidade cultural mútua, com um enfoque nas diferenças culturais. Ainda que seja percebido o elemento do exótico e ainda que a ideia de Descoberta seja eurocêntrica, é perceptível uma dobra discursiva. Neste Museu, permanece um silêncio sobre a violência da colonização, porém, também não é feita uma exaltação da colonização. Esse período praticamente não aparece, mantendo-se o foco no momento das Navegações e Descobertas.

Já no Museu dos Descobrimentos de Belmonte percebe-se a continuidade de um discurso luso-tropicalista que funde Descobrimentos e Colonização de maneira acrítica, utilizando os Descobrimentos de maneira apenas retórica para perpetuar a exaltação de um colonialismo benevolente. Neste Museu evidencia-se que o corpo colonial é (re)apresentado da mesma maneira que nas Exposições do Império: nu, disponível, subjugado e selvagem.

Por fim, diante das análises apresentadas, ressalta-se: (a) do ponto de vista prático, talvez seja possível a emergência de um discurso que exalte as Descobertas e critique a Colonização, podendo ser essa uma opção para equacionar o debate e construir espaços de memória que sejam críticos, reflexivos, feministas e antirracistas (denunciando as mazelas do colonialismo), e, ao mesmo tempo, reforcem uma ideia de nacionalidade portuguesa (valorizando o fato histórico das grandes navegações portuguesas); (b) do ponto de vista teórico, o conceito de corpo colonial se mostrou bastante profícuo para analisar o passado e o presente, reforçando a importância da perspectiva teórica acerca da interseccionalidade entre raça/colonialidade, gênero e sexualidade. Compreender as construções discursivas e as relações de poder no presente da sociedade moderna implica perceber as continuidades e rupturas com padrões de saber-poder racializados, generificados e sexualizados, construídos no período colonial.

\section{Referências}

ALMEIDA, Miguel Vale de. Um mar da cor da terra: raça, cultura e política de identidade. Oeiras: Celta, 2000. 
BALIBAR, Ełienne; WALLERSTEIN, Immanuel. Raza, Nación y Clase. Madrid: lepala, 1988.

BARATA, André. "A descolonização de um museu". Jornal Económico, Lisboa, 26/04/2018. Disponível em http://www.jornaleconomico.sapo.pt/noticias/a-descolonizacao-de-um-museu-298499. Acesso em 26/06/2018.

BEAUVOIR, Simone. O Segundo Sexo - volume único. Rio de Janeiro: Nova Fronteira, 2009 [1948].

BORELLI, Bruna. "Portugal ainda ensina o mito do bom colonizador". Jornal A Gazeta do Povo, São Paulo, 19 a 25 de maio de 2018. Disponível em https://www.gazetadopovo.com.br/educacao/ portugal-ainda-ensina-o-mito-do-bom-colonizador-84fksmzr8jbxu3pksxqd9kwc7/. Acesso em 26/ 06/2018.

BOURDIEU, Pierre. O Poder Simbólico. Lisboa: Bertrand, 2006.

BRAH, Avtar. "Diferença, diversidade, diferenciação". Cadernos Pagu, n. 26, p. 329-376, 2006.

BUTLER, Judith. Problemas de Gênero: Feminismo e Subversão da Identidade. Rio de Janeiro: Civilização Brasileira, 2008.

CALDWELL, Kia. "Fronteiras da diferença: raça e mulheres no Brasil". Revista Estudos Feministas, Florianópolis, v. 8, n. 2, p. 91-108, 2000.

CASTELO, Cláudia. O Modo português de estar no mundo: o luso-tropicalismo e a ideologia colonial portuguesa (1933-1961). Porto: Afrontamento, 1998.

CHADE, Jamil. "ONU critica Portugal por ensino inexato do passado". Estadão, São Paulo, 16/09/ 2012. Disponível em http://www.estadao.com.br/noticias/impresso,onu-critica-portugal-por-ensinoinexato-do-passado-, $931220,0 . \mathrm{htm}$. Acesso em 28/06/2018.

CHAGAS, Mário. “Memória política e política de memória”. In: CHAGAS, Mário; ABREU, Regina (Orgs.). Memória e Patrimônio: ensaios contemporâneos. Rio de Janeiro: DP\&A, 2003. p. 141-171.

CHOAY, Françoise. A alegoria do patrimônio. São Paulo: EDUNESP, 2001.

CRENSHAW, Kimberlé. "Documento para o Encontro de Especialistas em Aspectos da Discriminação Racial Relativos ao Gênero". Revista Estudos Feministas, v. 10, n. 1, p. 171-189, 2002.

CONNELL, Raewyn. "Masculinities and Globalization". Men and Masculinities, v. 1, n. 1, p. 3-23, 1998.

CUNHA, Olívia. "Reflexões sobre Biopoder e Pós-colonialismo: Relendo Fanon e Foucault”. Mana, v. 8, n. 1, p. 149-163, 2002.

DAVIS, Angela. Women, Race and Class. London: Great Britain, 1982.

DELEUZE, Gilles. Foucault. Lisboa: Vega, 1998.

DEUVREUX, Anne-Marie. "Pierre Bourdieu e as relações entre os sexos: uma lucidez obstruída". In: DEVREUX, Anne-Marie et al. (Orgs.). O Gênero nas Ciências Sociais. São Paulo/Brasília: EDUNESP/ EDUnB, 2014.

DIAS, Reinaldo. Turismo e patrimônio cultural: recursos que acompanham o crescimento das cidades. São Paulo: Saraiva, 2006.

FANON, Franz. Peles negras, máscaras brancas. Rio de Janeiro: Factor, 1983.

FOUCAULT, Michel. Microfísica do poder. São Paulo: Graal, 1986.

FOUCAULT, Michel. História da Sexualidade. v. 1 - A Vontade de Saber. Rio de Janeiro: Forense Universitária, 1993.

FOUCAULT, Michel. Genealogía del Racismo. Buenos Aires: Altamira, 1996.

FOUCAULT, Michel. Arqueologia do saber. Rio de Janeiro: Forense Universitária, 2004.

FOUCAULT, Michel. A Ordem do Discurso. São Paulo: Loyola, 2008.

GONÇALVES, Margareth. "Artifício e excesso: narrativa de viagem e a visão sobre as mulheres em 
Portugal e Brasil”. Revista Estudos Feministas, v. 13, n. 3, p. 613-628, 2005.

GONZALEZ, Lélia. "Por um feminismo afro-latino-americano". Revista Isis Internacional, v. IX, p. 133$141,1988$.

GOMES, Camilla. "Gênero como categoria de análise decolonial". Civitas, Porto Alegre, v. 18, n. 1, p. 65-82, jan./abr. 2018.

GOMES, Mariana. "O imaginário social < mulher brasileira> em Portugal: uma análise da construção de saberes, das relações de poder e dos modos de subjetivação". Dados - Revista de Ciências Sociais, v. 56, p. 867-900, 2013.

GOMES, Mariana. "Narrativas Patrimoniais e Turísticas em Salvador: (des)(re)construções do mito da democracia racial brasileira". In: ENCONTRO ANUAL DA ANPOCS, 38, 2014, Caxambu, ANPOCS. Anais... Caxambu: ANPOCS, 2014.

GOMES, Mariana; SILVA, Vagner; ALVES, Micheline; SOUSA, Lisandra; SANTOS, Bárbara. "O Turismo de Base Comunitária e o Enfrentamento ao Racismo e ao Sexismo: uma experiência no Quilombo Mocambo/SE". I SIMPOLITUR, 1, 2016, Aracaju, Instituto Federal de Sergipe. Anais... Aracaju: IFS, 2016.

GOMES, Mariana; PADILLA, Beatriz; FERNANDES, Gleiciane. "Ser brasileña en Portugal: inmigración, género y colonialidad". In: MAGLIANO, Maria José; BARRAL, Ana (Org.). Las mujeres latinoamericanas y sus migraciones. Villa María: Eduvim, 2017.

GREGÓRIO-GIL, Carmen. "Mujeres inmigrantes: Colonizando sus cuerpos mediante fronteras procreativas, étnico-culturales, sexuales y reproductivas". Viento Sur, n. 104, p. 42-54, 2009.

GUIMARÃES, Antônio Sérgio. Racismo e anti-racismo no Brasil. São Paulo: Editora 34, 2005.

HALBWACHS, Maurice. A Memória Coletiva. São Paulo: Vértice, 1990.

HIPÓLITO, Jéssica. "Subalternidade, Raça e Identidade: processos de construção identitária Negra em Museus Cariocas". CONGRESSO BRASILEIRO DE SOCIOLOGIA, 18, 2017, Brasília, Universidade de Brasília. Anais... Brasília: SBS, 2017.

hooks, bell et al. Otras Inapropriables: Feminismos desde las Fronteras. Madrid: Traficantes de Sueños, 2004.

HUYSSEN, Andreas. Seduzidos pela Memória: arquitetura, monumentos, mídia. Rio de Janeiro: Aeroplano, 2000.

LEE, Alison; PETERSEN, Alan. "Análise do Discurso". In: SOMEKH, Bridget; LEWIN, Cathy (Orgs.). Teoria e Métodos de Pesquisa Social. Petrópolis: Vozes, 2015.

LÓPEZ, Laura. "O Corpo Colonial e as Políticas e Poéticas da Diáspora para compreender as mobilizações Afro-Latino-Americanas". Horizontes Antropológicos, Porto Alegre, ano 21, n. 43, p. 301-330, jan./jun. 2015.

LUGONES, Maria. “Colonialidad y Género”. Tabula Rasa, n. 9, p. 73-101, 2008.

MARTINS, Leonor. Império de Papel: Imagens do Colonialismo Português na Imprensa Periódica Ilustrada (1875-1940). Lisboa: Edições 70, 2012.

MASON, Timothy. Gestão Museológica: Desafios e Práticas. São Paulo: EdUSP; British Council, Vitae, 2004.

McCLINTOCK, Anne. Couro Imperial: Raça, Gênero e Sexualidade no Embate Colonial. Campinas: EDUnicamp, 2010.

MIGNOLO, Walter; GROSFOGUEL, Ramón. "Intervenciones Descoloniales: una breve introducción”. Tabula Rasa, n. 9, p. 29-37, 2008.

MONTESANTI, Beatriz. "Instalação no MASP conta história de sufragistas que atacavam obras de arte". Folha de São Paulo, São Paulo, 17/1 1/2015. Disponível em http://www1.folha.uol.com.br/ ilustrada/2015/1 1/1 707532-instalacao-no-masp-traz-a-historia-das-sufragistas-que-atacavamobras-de-arte.shtml. Acesso em 28/06/2018. 
MUNANGA, Kabengele. Rediscutindo a Mestiçagem no Brasil: identidade nacional versus identidade negra. Petrópolis: Vozes, 1999.

NASCIMENTO, Elisa. O sortilégio da cor: identidade, raça e gênero no Brasil. São Paulo: Selo Negro, 2003.

NASCIMENTO, Rosana. O "Brasil Colonial" e a Exposição do Mundo Português de 1940. 2008. Tese (Doutorado em História) - Programa de Pós-Graduação em História, Universidade Federal da Bahia, Salvador, BA, Brasil.

NEAD, Lynda. The Female Nude: Art, Obscenity and Sexuality. Londres: Routledge, 1992.

OTO, Alejandro de. "Apuntes sobre historia y cuerpos coloniales: algunas razones para seguir leyendo a Fanon". Worlds \& Knowledges Otherwise, Durham, v. 1, n. 3, 2006.

OTO, Alejandro de. "Lugares fanonianos de la política: de la lengua al cuerpo y del cuerpo a la cultura nacional”. In: OLIVA, Elena et al. Frantz Fanon desde América Latina. Buenos Aires: Corregidor, 2013.

PEDRO, Joana. "Michelle Perrot: a grande mestra da História das Mulheres". Revista Estudos Feministas, Florianópolis, v. 11, n. 2, p. 509-512, jul./dez. 2003.

POLLAK, Michael. "Memória, esquecimento, silêncio". Estudos Históricos. Rio de Janeiro, CPDOC/ FGV, v. 2, n. 3, 1989.

QUIJANO, Aníbal. "Colonialidad del Poder, Eurocentrismo y América Latina”. In: LANDER, Edgardo (Org.). A Colonialidade do Saber: Eurocentrismo e Ciências Sociais. Perspectivas Latino-americanas. Buenos Aires: Colección Sur-Sur/CLACSO, 2005.

RECHENA, Aida. Sociomuseologia e Género: imagens da mulher em exposições de museus portugueses. 2011 . Tese (Doutorado em Museologia) - Programa de Doutoramento em Museologia, Universidade Lusófona de Humanidades e Tecnologias, Lisboa, Portugal.

RUIVO, Ana Lúcia. Corpo e Cultura: O Indígena Brasileiro nos Relatos Portugueses da segunda metade do Século XVI. 2010. Dissertação (Mestrado em Ensino do Português como Língua Segunda e Estrangeira) - Universidade Nova de Lisboa, Portugal.

SALEMA, Isabel. "É preciso descolonizar os descobrimentos". Público, Lisboa, 18/05/2018. Disponível em https://www.publico.pt/2018/05/18/culturaipsilon/entrevista/e-preciso-descolonizar-osdescobrimentos-1830262. Acesso em 26/06/2018.

SANCHES, Manuela. "A bem da Europa e das suas Nações. Em jeito de posfácio". In: MARTINS, Leonor. Um império de papel: imagens do colonialismo português na imprensa periódica ilustrada (1875-1940). Lisboa: Edições 70, 2012.

SANTOS, Beatriz. "Os números da violência contra as mulheres no Brasil". Exame, São Paulo, 08/03/ 2017. Disponível em https://exame.abril.com.br/brasil/os-numeros-da-violencia-contra-mulheresno-brasil/. Acesso em 26/06/2018.

SCOTT, Joan. "Gender: A Useful Category of Historical Analysis". The American Historical Review, v. 91, n. 5, p. 1053-1075, 1986.

SKIDMORE, Thomas. Preto no branco: raça e nacionalidade no pensamento brasileiro. Rio de Janeiro: Paz e Terra, 1989.

STOLKE, Verena. "O enigma das intersecções: classe, raça, sexo, sexualidade. A formação dos impérios transatlânticos do século XVI ao XIX". Revista Estudos Feministas, v. 14, n. 1, p. 15-42, 2006.

VASCONCELLOS, Camilo. Turismo e Museus. São Paulo: Aleph, 2006.

Mariana Selister Gomes (marianaselister@gmail.com) é Professora Adjunta do Departamento de Ciências Sociais, do Programa de Pós-Graduação em Ciências Sociais e do Programa de Pós-Graduação em Relações Internacionais da Universidade Federal de Santa Maria (UFSM). Doutora em Sociologia pelo Instituto Universitário de Lisboa (ISCTE-IUL). Mestre em Sociologia e Bacharel em História pela UFRGS. Bacharel em Turismo pela PUCRS. 


\section{COMO CITAR ESSE ARTIGO DE ACORDO COM AS NORMAS DA REVISTA}

GOMES, Mariana Selister. "Dos Museus dos Descobrimentos às Exposições do Império: o Corpo Colonial em Portugal”. Revista Estudos Feministas, Florianópolis, v. 27, n. 3, e57903, 2019.

\section{CONTRIBUIÇÃO DE AUTORIA}

Não se aplica.

\section{FINANCIAMENTO}

Pesquisa de Campo em Portugal. O presente trabalho foi realizado com apoio da Coordenação de Aperfeiçoamento de Pessoal de Nível Superior - Brasil (CAPES) - Código de Financiamento 001, por meio da Chamada Pública $n^{\circ} 43 / 2013$.

\section{CONSENTIMENTO DE USO DE IMAGEM}

Não se aplica.

APROVAÇÃO DE COMITÊ DE ÉTICA EM PESQUISA

Não se aplica.

\section{CONFLITO DE INTERESSES}

Não se aplica.

\section{LICENÇA DE USO}

Este artigo está licenciado sob a Licença Creative Commons CC-BY International. Com essa licença você pode compartilhar, adaptar, criar para qualquer fim, desde que atribua a autoria da obra.

\section{HISTÓRICO}

Recebido em 27/06/2018

Reapresentado em 09/03/2019

Aprovado em 27/03/2019 